\title{
WIRELESS COMMUNICATION SYSTEM FOR MONITORING HEART RATE IN THE DETECTION AND INTERVENTION OF EMOTIONAL REGULATION
}

\author{
Paper ID: 1570599244 \\ Syahid Al Irfan (Universitas Ahmad Dahlan, Indonesia); Anton Yudhana (Ahmad \\ Dahlan University, Indonesia); Ismail Karas (Karabuk University, Turkey); Dewi Eko \\ Wati and Intan Puspitasari (Ahmad Dahlan University, Indonesia)
}

\begin{abstract}
Based on data from the Indonesian Child Protection Commission (KPAl) cases of violence against children from 2010 to 2015 continued to increase which from 2010 only 171 cases increased to 2015 as many as 6006 which means that every year cases of violence against children continues to increase at least 1000 cases each year. Changes in heart rate in humans can be known through the flow of blood that flows in blood vessels. As the heart beats, the flow in the blood vessels will move so that is when the condition of the heart rate can be measured. In this study a wireless heart rate condition data collection system will be developed and a heart rate sensing device that has the same ability as a device used in general medical activities. There are three main components, namely server, access point and devices. The three components are summarized in one system, the loT system. The sensor data obtained is sent via a wireless network using the HTTP Request data sending method. With this method the data transmission is carried out through the HTTP protocol and received and processed by the server with a programming language which in this study used the PHP programming language.
\end{abstract}

Keywords: Wireless Comunication; MAX30100; XAMPP 